\title{
The therapeutic behaviour of patients with coronary heart disease from the perspective of their social characteristics
}

\author{
Maria Iakovleva* and Olga Shchelkova \\ Saint Petersburg State University, Saint Petersburg, Russian Federation
}

\begin{abstract}
The main issue for patients with chronic illnesses (CVD among them) is the long-term health management. A high level of adherence to prescribed treatment leads to a great therapeutic benefit, but many patients follow it to a small extent or do not follow it at all. The existing data on concrete adherence factors is controversial. The aim of the study consisted in investigating the social factors of adherence to treatment in patients with coronary heart disease. The patients $(n=103)$ were interviewed, examined and questionnaires received. It was found that patients' strong motivation to continue working related to self-realization and the presence of great interest in their job, as well as the presence of social support are factors which are significantly associated with higher adherence to treatment. Further comprehensive studies of adherence factors related to the patient are required.
\end{abstract}

\section{Introduction}

It is evident that for patients with chronic illnesses (such as asthma, diabetes, hypertension, and some others) the main issue is the long-term, sometimes life-long, health management. Despite the proven fact that a high level of adherence to prescribed treatment leads to a great therapeutic benefit, many patients follow it to a small extent or do not follow it at all. Summarizing the data obtained from large amount of investigations, the World Health Organization reported that in developed countries approximately $50 \%$ of patients with chronic diseases do not take medications as prescribed [1]. It was proved that low adherence to treatment is a significant barrier to optimal patient care, and non-adherence often leads to an increase in patients' morbidity and health care costs. For example, in the United States, 33-69\% of all medication-related hospitalizations are associated with poor medication adherence, resulting in approximately 125.000 deaths per year and an estimated $\$ 100$ billion annually [2].

Regardless of general awareness and the above-mentioned empirical data on the harms associated with non-adherence, improving both medication and non-pharmacological adherence in chronic diseases continues being challenging, due to its complex and patientspecific nature [3].

Adherence to treatment is crucial for patients suffering from cardiovascular diseases because of the high mortality risk $[4,5]$. According to the European Society of Cardiology statistics, the mortality from coronary heart disease (CHD) in Russia is one of the highest in Europe [6]. In 2017, the mortality from CHD in the Russian Federation amounted to 456.617

\footnotetext{
* Corresponding author: m.v.yakovleva@spbu.ru; mariaiakovleva@mail.ru
}

(C) The Authors, published by EDP Sciences. This is an Open Access article distributed under the terms of the Creative Commons Attribution License 4.0 (http://creativecommons.org/licenses/by/4.0/). 
persons [7]; and although it has slightly decreased in the recent years (cf. 477.579 persons in 2016), it remains being the main cause of mortality [Ibid.].

The surgical treatment of CHD is highly effective and widespread. However, to reach high rates in health outcomes, patients are required to follow the postoperative regimen. Rehabilitation programs are aimed at reduction of mortality and morbidity rates among CHD patients after cardiac surgery, but adherence to such programs has been found to be poor [8]. It is also worth noting that consideration of adherence to treatment in CHD patients should include a large number of aspects in addition to the drug therapy, since lifestyle changes are the key factor, which increases their life expectancy and accelerates their recovery after surgical treatment.

The question about the causes of the patients' therapeutic behaviour remains open. Previous studies have shown the relationship between adherence to treatment and various aspects, some of them related to patients' social and psychological characteristics, to their attitude towards the disease, to the type of the disease itself, to the relations between the patient and the medical care provider, therefore we can say that the reasons for adherence or non-adherence are multi-factorial.

Still, the existing data on concrete adherence factors is controversial therefore to continue the research of the whole complex of factors seems significant for both: for the health care system as a whole, and for each concrete patient. In particular, the study of social factors is very important because they are closely related with patients' behaviour in the therapy process, including their perception of the disease and their potential of fulfilling the prescribed recommendations.

According to the aforesaid, the aim of the study was investigation of the social factors of adherence to treatment in patients with coronary heart disease.

\section{Material and methods}

The research set several tasks, among them were the following:

- to study the social characteristics of CHD patients who underwent CABG surgery: their marital, parental, educational, occupational, material status, etc.;

- to assess the level of adherence to treatment of patients after CABG and to divide the patients into groups according to this level;

- to make a comparative analysis of the social characteristics of patients from adherent and non-adherent to treatment groups; to identify the social characteristics statistically related to the level of adherence to treatment.

The preparatory phase and the pilot study have been conducted since 2014. As a result, optimal research methods were selected, lists of questions for the questionnaire and criteria for selecting subjects were formulated. The radix presented in this article was recruited in subsequent years (2015-2017); the study is currently ongoing according to an expanded plan.

The research plan was developed and discussed by the scientific team that involved both academic specialists and clinicians with practical experience in the field. The presented results form part of the ongoing global study in the field of psycho-cardiology and rehabilitation, which have passed a scientific and ethical review in the Russian Foundation for Basic Research (RFBR) and was supported by it.

For fulfilling the purpose of the investigation, patients of the Federal Almazov NorthWest Medical Research Centre (Saint Petersburg, Russian Federation) suffering from cardiovascular diseases were involved in the research. When entering the hospital department patients gave their written consent to the therapy, as well as all the necessary medical and 
psychological examinations. The study described in this article was also conducted with the consent of patients. They were informed on the purpose of the research and use of the data.

The patients' health condition in regard with their illness was rather severe and therefore there were indications for surgical treatment, which was performed in the same medical institution. However, those patients who had severe co-morbidities in an acute condition or experienced postoperative complications were excluded from the sample. In total 103 patients with coronary heart disease who underwent coronary artery bypass grafting (CABG) were examined. The average age in the sample was $60.14 \pm 8.95$ years.

Patient data was collected by means of interviews with patients and their physicians, as well as filling out a special questionnaire - a structured form, which consisted in a list of questions grouped into sections: clinical characteristics, demographic characteristics, social characteristics, economic characteristics and some others. In general, the interview with a patient should not have taken more than 1.5 hours to eliminate the exhaustion of the subjects. The assessment of patients' physical condition was carried out taking into account the information from medical records and the physicians' evaluation.

All patients were under the regular supervision of cardiologists and underwent regular check-ups to ensure full knowledge about each patient.

Evaluation of adherence to treatment was carried out according to the specifics of the cardiovascular diseases (CHD in particular) and necessarily included the consideration of factors from two main blocks:

- pharmacological treatment (regular intake of the drugs and their correct dosage),

- non-drug treatment (weight control and control of blood pressure, physical training and diet, smoking and alcohol cessation).

Most of treatment adherence questionnaires focus mainly on pharmacological therapy. In this regard, it was decided to use an expert method based on long-term monitoring of patients and their questioning. Patients who were found to take the prescribed drugs regularly and in the right doses, to follow the recommended diet and physical activity, as well as quitting bad habits, were assigned to the adherent to treatment group. The group of non-adherent patients was made up of subjects who, despite being informed of the correct treatment, refused to take the medicine or took them not regularly but symptomatically. They led an inappropriate lifestyle and did not control their health indicators, refusing to follow the recommendations for active therapy.

A group of specialists - cardiologists and clinical psychologists-conducted the assessment of the patients' adherence to treatment level to ensure maximum reliability of the data obtained.

To compare the results of the research in groups of patients being adherent and nonadherent to treatment, the significance of differences in the frequency of responses was evaluated using analysis of nominative data: cross tables analysis, Pearson's chi-squared test, differences in average values were calculated using the Mann-Whitney U-test.

\section{Results and discussion}

The implementation of the approach, which considers a patient as an integral phenomenon (i.e. the biopsychosocial model), taking into account all their traits and characteristics, makes it possible to understand patient's therapeutic behaviour with all its specifics and motives. In order to achieve the aims of our research several patients' social characteristics such as their background, professional experience and family were studied. 
Table 1. Distribution of the studied CHD patients by gender (N,\%).

\begin{tabular}{|l|c|c|c|c|c|c|}
\hline \multirow{2}{*}{$\begin{array}{l}\text { Patients' } \\
\text { gender }\end{array}$} & \multicolumn{2}{|c|}{$\begin{array}{c}\text { I. Adherent to treatment } \\
\text { patients }(\boldsymbol{n}=\mathbf{5 3})\end{array}$} & \multicolumn{2}{|c|}{$\begin{array}{c}\text { II. Non-adherent to } \\
\text { treatment patients }(\boldsymbol{n}=\mathbf{5 0})\end{array}$} & \multicolumn{2}{|c|}{$\begin{array}{c}\text { Total } \\
(\boldsymbol{n}=\mathbf{1 0 3})\end{array}$} \\
\cline { 2 - 7 } & $\mathbf{N}$ & $\mathbf{\%}$ & $\mathbf{N}$ & $\mathbf{\%}$ & $\mathbf{N}$ & $\mathbf{\%}$ \\
\hline - male & 43 & 81.1 & 42 & 84.0 & 85 & 82.5 \\
- female & 10 & 18.9 & 8 & 16.0 & 18 & 17.5 \\
\hline
\end{tabular}

Table 2. Distribution of the studied CHD patients by education (N, \%).

\begin{tabular}{|l|c|c|c|c|c|c|}
\hline $\begin{array}{l}\text { Patients' } \\
\text { education } \\
\text { level }\end{array}$ & \multicolumn{2}{|c|}{$\begin{array}{c}\text { I. Adherent to treatment } \\
\text { patients }(\boldsymbol{n}=\mathbf{5 3})\end{array}$} & \multicolumn{2}{|c|}{$\begin{array}{c}\text { II. Non-adherent to } \\
\text { treatment patients }(\boldsymbol{n}=\mathbf{5 0})\end{array}$} & \multicolumn{2}{|c|}{$\begin{array}{c}\text { Total } \\
(\boldsymbol{n}=\mathbf{1 0 3})\end{array}$} \\
\cline { 2 - 7 } & $\mathbf{N}$ & $\mathbf{\%}$ & $\mathbf{N}$ & $\mathbf{\%}$ & $\mathbf{N}$ & $\%$ \\
\hline - elementary & 2 & 3.77 & 1 & 2.00 & 3 & 2.91 \\
- secondary & 11 & 20.76 & 9 & 18.00 & 20 & 19.42 \\
- vocational & 15 & 28.30 & 19 & 38.00 & 34 & 33.01 \\
- incomplete higher & 1 & 1.89 & 4 & 8.00 & 5 & 4.85 \\
- higher & 24 & 45.28 & 17 & 34.00 & 41 & 39.81 \\
\hline
\end{tabular}

The analysis of these characteristics showed that some of the factors are significantly related to patients' implementation of the medical regimen while other characteristics were less significant in determining patients' therapeutic behaviour.

\subsection{General characteristics}

Since there is evidence of gender differences in patients' behaviour in the therapy process [9], it seemed necessary to consider the distribution of the sample by gender (Table 1).

The study involved 85 men (43 of them adherent to treatment - group I, and 42 non-adherent - group II) and 18 women (10 adherent to treatment - group I, and 8 non-adherent - group II). The specifics of this disease and this kind of surgical treatment caused such an uneven distribution of patients by gender. In this regard, it appears to be difficult and even incorrect to assess the greater tendency of men or women for adherent or non-adherent behaviour in the process of therapy. In the future, a detailed study of male and female patients and the specific characteristics of both groups related to their adherence to treatment is planned.

The study of patients' education level allowed us to get the following data (Table 2).

According to the findings, about half of the patients adherent to therapy have a university degree $(45 \%)$, while among non-adherent patients the rates on education were the following: technical and vocational training was ranked as the most common (38\%), but higher education took the second place (34\%), which is common for this age category. About one fifth of the patients in both groups have secondary education $(21 \%$ and $18 \%$, respectively), but among the studied patients this factor did not prevent them from good implementation of medical recommendations. Summing up, no significant differences in patients' education level regarding their adherence to treatment after CABG were found.

Undoubtedly, the level of education can be a factor influencing the behaviour of patients in the course of therapy [10,11], but its influence is not so straightforward [12]. It is also necessary to note that we must not identify the education itself with health literacy, which is known to be a reliable factor, increasing adherence to treatment $[8,11,13-15]$. 
Table 3. Distribution of the studied CHD patients by their marital and parental status (N, \%).

\begin{tabular}{|c|c|c|c|c|c|c|}
\hline \multirow[t]{2}{*}{$\begin{array}{l}\text { Patients' family } \\
\text { characteristics }\end{array}$} & \multicolumn{2}{|c|}{$\begin{array}{c}\text { I. Adherent to } \\
\text { treatment patients } \\
(n=53)\end{array}$} & \multicolumn{2}{|c|}{$\begin{array}{l}\text { II. Non-adherent to } \\
\text { treatment patients } \\
\qquad(n=50)\end{array}$} & \multicolumn{2}{|c|}{$\begin{array}{c}\text { Total } \\
(n=103)\end{array}$} \\
\hline & $\mathbf{N}$ & $\%$ & $\mathbf{N}$ & $\%$ & $\mathbf{N}$ & $\%$ \\
\hline $\begin{array}{l}\text { Marital status } \\
\text { - single } \\
\text { - common-law marriage } \\
\text { - married } \\
\text { - divorced } \\
\text { - widowed }\end{array}$ & $\begin{array}{c}1 \\
2 \\
45 \\
2 \\
3\end{array}$ & $\begin{array}{c}1.89 \\
3.77 \\
84.91 \\
3.77 \\
5.66\end{array}$ & $\begin{array}{c}2 \\
5 \\
31 \\
6 \\
6\end{array}$ & $\begin{array}{l}4.00 \\
10.00 \\
62.00 \\
12.00 \\
12.00\end{array}$ & $\begin{array}{c}3 \\
7 \\
76 \\
8 \\
9\end{array}$ & $\begin{array}{c}2.91 \\
6.80 \\
73.79 \\
7.76 \\
8.74\end{array}$ \\
\hline Parental status & & & & & & \\
\hline $\begin{array}{l}\text { - } \text { no children } \\
\text { - } 1 \text { child } \\
\text { - } 2 \text { children } \\
\text { - } 3 \text { and more children }\end{array}$ & $\begin{array}{c}2 \\
19 \\
26 \\
6\end{array}$ & $\begin{array}{c}3.77 \\
35.85 \\
49.06 \\
11.32\end{array}$ & $\begin{array}{c}3 \\
24 \\
20 \\
3\end{array}$ & $\begin{array}{c}6.00 \\
48.00 \\
40.00 \\
6.00\end{array}$ & $\begin{array}{c}5 \\
43 \\
46 \\
9\end{array}$ & $\begin{array}{c}4.85 \\
41.75 \\
44.66 \\
8.74\end{array}$ \\
\hline
\end{tabular}

\subsection{Characteristics related to patients' family}

The next aspect studied on the sample of CHD patients was their marital status and whether they have children or not. The results are presented in the Table 3.

The presented data seem to be of great significance, since the presence of a close person, a significant one who supports the patient during the treatment, is an important factor preventing from the violation of the medical regime [11]. The spouse can help the patient to monitor the new lifestyle related to his/her disease and health status, starting with the regularity of medication intake and ending with physical activity and diet. In the present sample, there were no statistically significant differences in the marital status of patients from the two groups. However, it is noted that among those patients who are adherent to treatment, the majority are married (85\%), while in the group of non-adherent to treatment patients this figure was only $62 \%$.

We believe that the study of marital status itself, apart from other psychosocial characteristics cannot provide complete data on the situation in the family of the patient. It seems appropriate and needful to collect detailed psychological data, such as the presence of a significant person in the patient's environment, the presence of understanding and support provided by the family of the patient during the treatment, the assignment of active or passive roles between the patient and his/her relatives in the process of fulfilling the medical recommendations.

\subsection{Characteristics related to patients' job}

Patients' employment and job characteristics represent an important aspect in determining their behaviour in the treatment process. The existing studies report the relationship between patients' job and adherence to therapy in cardiovascular diseases [11] and therefore patients' professional experience was the object of our study, too (Tables 4, 6, 7).

As we have already mentioned, the research was aimed at studying of the occupational activity of patients. Their professional status by the time of surgery is presented in the Table 4 . About half of the patients from both groups had a permanent job (49\% vs. 50\%), which they planned to continue after $\mathrm{CABG}$, in case of absence of medical contraindications. The majority of patients noted that a large amount of stress, emotional and intellectual load are present or used to be present at their work $(87 \%$ vs. $92 \%)$; some patients also stated the presence of physical overloads (42\% vs. $36 \%$ ) and occupational hazards (32\% vs. 24\%). 
Table 4. Distribution of the studied CHD patients by their professional status (N, \%).

\begin{tabular}{|c|c|c|c|c|c|c|}
\hline \multirow[t]{2}{*}{$\begin{array}{l}\text { Patients' job } \\
\text { characteristics }\end{array}$} & \multicolumn{2}{|c|}{$\begin{array}{c}\text { I. Adherent to } \\
\text { treatment patients } \\
(n=53)\end{array}$} & \multicolumn{2}{|c|}{$\begin{array}{l}\text { II. Non-adherent to } \\
\text { treatment patients } \\
\quad(n=\mathbf{5 0})\end{array}$} & \multicolumn{2}{|c|}{$\begin{array}{c}\text { Total } \\
(n=\mathbf{1 0 3})\end{array}$} \\
\hline & $\mathbf{N}$ & $\%$ & $\mathbf{N}$ & $\%$ & $\mathbf{N}$ & $\%$ \\
\hline Labour activity & \multirow[b]{2}{*}{$\begin{array}{c}26 \\
1 \\
2 \\
8 \\
16\end{array}$} & \multirow[b]{2}{*}{$\begin{array}{c}49.06 \\
1.89 \\
3.77 \\
15.09\end{array}$} & \multirow[b]{2}{*}{$\begin{array}{c}25 \\
4 \\
5 \\
5 \\
11\end{array}$} & \multirow[b]{2}{*}{$\begin{array}{c}50.00 \\
8.00 \\
10.00 \\
10.00 \\
\\
22.00\end{array}$} & \multirow[b]{2}{*}{$\begin{array}{c}51 \\
5 \\
7 \\
13 \\
\\
27\end{array}$} & \multirow[b]{2}{*}{$\begin{array}{r}49.52 \\
4.85 \\
6.80 \\
12.62 \\
26.21\end{array}$} \\
\hline $\begin{array}{l}\text { - full-time employment } \\
\text { - irregular job } \\
\text { - unemployed } \\
\text { - part-time employment due } \\
\text { to senior age } \\
\text { - retired }\end{array}$ & & & & & & \\
\hline Job description & \multirow[b]{2}{*}{$\begin{array}{l}22 \\
46 \\
17\end{array}$} & \multirow[b]{2}{*}{$\begin{array}{l}41.51 \\
86.79 \\
32.08\end{array}$} & \multirow[b]{2}{*}{$\begin{array}{l}18 \\
46 \\
12\end{array}$} & \multirow[b]{2}{*}{$\begin{array}{l}36.00 \\
92.00 \\
24.00\end{array}$} & \multirow[b]{2}{*}{$\begin{array}{l}40 \\
92 \\
29\end{array}$} & \multirow[b]{2}{*}{$\begin{array}{l}38.84 \\
89.32 \\
28.16\end{array}$} \\
\hline $\begin{array}{l}\text { - presence of physical load } \\
\text { - presence of mental load } \\
\text { - presence of work-related exposure }\end{array}$ & & & & & & \\
\hline
\end{tabular}

Table 5. Distribution of the studied CHD patients by their income level (N, \%).

\begin{tabular}{|l|c|c|c|c|c|c|}
\hline \multirow{2}{*}{$\begin{array}{l}\text { Patients' financial } \\
\text { status }\end{array}$} & \multicolumn{2}{|c|}{$\begin{array}{c}\text { I. Adherent to } \\
\text { treatment patients } \\
(\boldsymbol{n}=\mathbf{5 3})\end{array}$} & $\begin{array}{c}\text { II. Non-adherent to } \\
\text { treatment patients } \\
(\boldsymbol{n}=\mathbf{5 0})\end{array}$ & \multicolumn{2}{|c|}{$\begin{array}{c}\text { Total } \\
(\boldsymbol{n}=\mathbf{1 0 3})\end{array}$} \\
\cline { 2 - 7 } & $\mathbf{N}$ & $\mathbf{\%}$ & $\mathbf{N}$ & $\boldsymbol{\%}$ & $\mathbf{N}$ & $\mathbf{\%}$ \\
\hline - absence of financial difficulties & 45 & 84.91 & 36 & 72.00 & 81 & 78.64 \\
- presence of financial difficulties & 8 & 15.09 & 14 & 28.00 & 22 & 21.36 \\
\hline
\end{tabular}

For these two indicators, the values of non-adherent patients are lower, but no statistically significant differences were found between the two groups regarding their work life.

\subsection{Characteristics related to patients' financial status}

Among the aspects studied in the sample of CHD patients in regard to their adherence to treatment was their financial status (Table 5).

As seen from the data presented in the Table 5, in the surveyed sample no differences between the welfare of the adherent and non-adherent patients were found. However, this aspect requires further study, since being on a tight budget is an objective factor that often prevents patients from following all the medical advisers' recommendations. Previous researches differ in defining the significance of the patients' income level in determining their level of adherence to treatment $[11,16]$, while recognizing the existence of financial difficulties as a factor that reduces adherence (for example, the high cost of drugs may lead to therapy non-adherence in patients with low income [11]).

\subsection{Patients' characteristics associated with adherence to treatment}

Despite the fact that no relationship was revealed between the above-mentioned characteristics and adherence to treatment, statistically significant differences between patients from the two groups were found in terms of some factors related to their social characteristics. 
Table 6. Presence of motives for continuing working among the studied CHD patients (N, \%).

\begin{tabular}{|l|c|c|c|c|c|c|}
\hline $\begin{array}{l}\text { Motive for employment } \\
\text { after CABG among patients } \\
\text { who continued working }\end{array}$ & $\begin{array}{c}\text { I. Adherent to } \\
\text { treatment patients } \\
(\mathbf{n}=33)\end{array}$ & $\begin{array}{c}\text { II. Non-adherent to } \\
\text { treatment patients } \\
(\boldsymbol{n}=\mathbf{3 6})\end{array}$ & \multicolumn{2}{|c|}{$\begin{array}{c}\text { Total } \\
(\boldsymbol{n}=69)\end{array}$} \\
\cline { 2 - 8 } & $\mathbf{N}$ & $\%$ & $\mathbf{N}$ & $\%$ & $\mathbf{N}$ & $\%$ \\
\hline Self-realization & 17 & 51.52 & 8 & 22.23 & 25 & 36.23 \\
\hline \multicolumn{7}{|c|}{$\chi^{2}=4,719 p<0.05$} \\
\hline Interest in the job & 23 & 69.70 & 14 & 38.89 & 37 & 53.62 \\
\hline
\end{tabular}

In particular, the desire to continue working, the reluctance to take the role of a sick person leads to more patients' attention to the therapeutic regimen. Thus, among patients who plan to continue work after surgery or have already returned to work (in total 69 persons out of 103 studied patients), a number of aspects are statistically reliably associated with a higher level of adherence to treatment.

During the interview patients were asked about their motives for continuing work. Among the leading motives, economic (stable income, financial independence or the chance for helping the children), social (associated with the desire to be in a team, unwillingness to go into illness and "fall out" from active life) were named. However, there were two motives, in the presence of which there was a statistically significant difference between patients from the two groups (Table 6).

Patients whose behaviour is adherent to the recommendations of doctors, significantly more often referred to self-realization as one of the motives for continuing labour activity than non-adherent patients (52\% and $22 \%$, respectively). The desire of personal growth in spite of the disease often characterizes the patients who take the therapeutic regimen seriously $\left(\chi^{2}=4.719 ; p<0.05\right)$. A higher level of consciousness and a responsible attitude towards one's health, an awareness of the consequences of the violation of the therapeutic regimen leads to a higher and more stable level of adherence to treatment.

Patients from the first group were also more likely than patients from the second group to indicate the motive of interest in their current job for continuing working (70\% vs. 39\%; $\left.\chi^{2}=6.359 ; p<0.05\right)$. This motive is closely related to the first one; it also demonstrates the active life position of patients and the desire for self-evolution through an interesting and enjoyable work.

In the course of the study, was revealed another factor, partly related to the patient's work activity, which was significantly associated with adherence to treatment.

It is a well-known fact that the patients' relationships (in all life spheres) are of great importance for their behaviour in the process of therapy $[16,17]$. The relationship in the patients' families was mentioned earlier in this article. The data concerning relations in the work group, also obtained in this research, presents some interest (Table 7).

All patients, including those who were retired and currently unemployed, were interviewed about the quality of relationships in their work team (or former team). Patients from the first group (adherent to treatment) more often indicated positive, friendly relations with colleagues (74\%), the presence of colleagues' support and understanding, the opportunity to ask for their help $\left(\chi^{2}=8.617 ; p<0.05\right)$. Moreover, the mentioned relationships have often persisted after quitting the job. For example, retired patients noted that at one time their relations in the work team were very supportive, and nowadays many of their colleagues have become their friends, they continue being in touch and also perceive support from them. Non-adherent to treatment patients reported the presence of such a relationship only in $46 \%$. 
Table 7. Distribution of the studied CHD patients by their relationship in the working team (N, \%).

\begin{tabular}{|l|c|c|c|c|c|c|}
\hline $\begin{array}{l}\text { Patients' relations } \\
\text { with colleagues }\end{array}$ & \multicolumn{2}{|c|}{$\begin{array}{c}\text { I. Adherent to } \\
\text { treatment } \\
\text { patients }(\boldsymbol{n = 5 3 )}\end{array}$} & $\begin{array}{c}\text { II. Non-adherent } \\
\text { to treatment } \\
\text { patients }(\boldsymbol{n}=\mathbf{5 0})\end{array}$ & \multicolumn{2}{|c|}{$\begin{array}{c}\text { Total } \\
(\boldsymbol{n}=\mathbf{1 0 3})\end{array}$} \\
\cline { 2 - 7 } & $\mathbf{N}$ & $\mathbf{\%}$ & $\mathbf{N}$ & $\%$ & $\mathbf{N}$ & $\%$ \\
\hline - good, friendly & 39 & 73.59 & 23 & 46.00 & 62 & 60.19 \\
- formal, conventional & 12 & 22.64 & 25 & 50.00 & 37 & 35.92 \\
- negative, hostile & 2 & 3.77 & 2 & 4.00 & 4 & 3.89 \\
\hline \multicolumn{7}{|c|}{$\chi^{2}=8.617 p<0.05$} \\
\hline
\end{tabular}

It seems obvious that this characteristic is quite subjective and strongly depends on the perception of the patients. Some personality traits of patients, such as openness, friendliness can lead to the above described perception of relationships in a team. However, it is also clear that such a perception gives patients the much-needed support and strengthens their desire to continue treatment.

Thereby to date there is still an urgent need of studying the psychological characteristics of patients, in particular their personality traits, attitude towards the disease and provided treatment, and many others [18].

\subsection{Discussion and limitations of the research}

Adherence to treatment, regardless of the apparent simplicity of the term, is a complex phenomenon - it does not just consist of many different behavioral aspects of the patient, including a whole set of complex actions that require a conscious approach to one's health and a high degree of awareness and health literacy, but is also propelled by a wide range of factors related to the patient's personality, healthcare system and their relationship (in particular, between the patient and the attending physician). The factors associated with the treatment are quite well studied and can be modified - for example, replacing a large number of pills taken by the patients to an easier and a more convenient pharmacotherapy regimen may improve adherence [19]. However, factors associated with the patient himself are often more controversial and complex. Each of the many characteristics of the patient -age, gender, employment, personality traits, cognitive attitudes, previous treatment experience-in any given case may turn out to be a determinative factor that interferes with adherence to the doctors' recommendations [20].

The obtained data regarding the social characteristics of patients (albeit in a relatively small sample so far) once again indicates that the patient's personality cannot be excluded from consideration when planning and evaluating the effectiveness of high-tech surgical treatment.

At this stage, no significant differences were found between adherent and non-adherent to treatment patients according to their marital status, level of education, and specifics of their job. However, it may prove that the problem of low adherence to treatment can be found among all groups of patients - men and women, who are actively working and retired, with a high level of education, including a scientific degree, and with basic school education.

At the same time, the established associations allow us to state the factors indicating a greater probability of adherent behaviour of CHD patients after heart surgery. An active life position, manifested in the specifics of attitude to work, as well as the presence of support in various life spheres of patients, are factors associated with a more responsible approach to their health and, therefore, favorably affect the therapeutic behaviourof patients. 
In conclusion, it is worth noting once again that the examined patients underwent hightech surgical intervention, which significantly improves their well-being and the quality of life. Thereby, the percentage of further therapy rejection is high. The specifics of this operation must be taken into account when comparing our results with the results for patients undergoing conservative treatment.It is also necessary to take into account the rather high average age of patients from the sample.

As it was mentioned above, the patients' social characteristics statistics in themselves may not be very informative; they should be interpreted taking into account the psychological characteristics of patients, considering each patient individually, in order to determine what became a decisive factor that influenced patient's behaviour in the process of high-tech treatment of coronary heart disease.

\section{Conclusions}

Increasing the effectiveness of therapy remains one of the key objectives of the health care system. In cardiovascular diseases one of the leading factors associated with this problem is the behaviour of patients in the therapy process. As it has been proven by numerous studies, improving patients' adherence to medication and adherence to a new disease-related lifestyle requires a multifaceted and patient-specific approach. Thereafter, it is necessary to study the factors of adherent and non-adherent patients' behaviour, including their social characteristics; the significance of such factors in determining patients' therapeutic behaviour was confirmed in the present study. This will allow revealing in advance the risk factors of non-adherence in a concrete patient.

This research was supported by the Russian Foundation for Basic Research (RFBR) (Grant No 18-01300689 A).

\section{References}

[1] World Health Organization, Adherence to long-term therapies, evidence for action (WHO, Geneva, 2003)

[2] L. Osterberg, T. Blaschke, N. Engl. J. Med. 353, 487-497 (2005)

[3] A.B. Oung, E. Kosirog, B. Chavez, J. Brunner, J.J. Saseen, Ther Adv Chronic Dis. 8(8-9), 113-120 (2017)

[4] E.C. Gathright, M.A. Dolansky, J. Gunstad, J.D. Redle, R.A. Josephson, S.M. Moore, J.W. Hughes, Health Psychol. 36(9), 839-847 (2017)

[5] J.R. Wu, S.K. Frazier, M.K. Rayens, T.A. Lennie, M.L. Chung, D.K. Moser, Health Psychol. 32(6), 637-46 (2013)

[6] N. Townsend, L. Wilson, P. Bhatnagar, K. Wickramasinghe, M. Rayner, M. Nichols, Eur. Heart J. 37(42), 3232-3245 (2016)

[7] Sotsial'no-ekonomicheskoepolozhenieRossii: 2017 [Socio-economic situation in Russia: 2017] (Federal State Statistics Service Publ., Moscow, 2018) (In Russ.)

[8] G.H. Taylor, S.L. Wilson, J. Sharp, J. Cardiovasc Nurs. 26(3), 202-9 (2011)

[9] B.B. Granger, I. Ekman, C.B. Granger, J. Ostergren, B. Olofsson, E. Michelson, J.J. McMurray, S. Yusuf, M.A. Pfeffer, K. Swedberg, Eur. J. Heart Fail. 11, 1092-8 (2009)

[10] L.S. Evangelista, J. Berg, K. Dracup, Heart Lung: J. Crit. Care 30(4), 294-301 (2001)

[11] P. Karakurt, M. Kaşikçi, J. VascNurs. 30(4), 118-26 (2012) 
[12] R. Oosterom-Calo, A.J. van Ballegooijen, C.B. Terwee, S.J. te Velde, I.A. Brouwer, T. Jaarsma, J. Brug, Heart Fail Rev. 18(4), 409-27 (2013)

[13] C. Alm-Roijer, M. Stagmo, G. Udén, L. Erhardt, Eur. J. Cardiovasc Nurs. 3(4), 321-30 (2004)

[14] M.H. van der Wal, T. Jaarsma, Int. J. Cardiol. 125(2), 203-8 (2008)

[15] J.A. Gazmararian, S. Kripalani, M.J. Miller, K.V. Echt, J. Ren, K. Rask, J. Gen. Intern Med. 21(12), 1215-21 (2006)

[16] J.R. Wu, D.K. Moser, M.L. Chung, T.A. Lennie, J. Card. Fail. 14(7), 603-14 (2008)

[17] L.G. Park, J. Howie-Esquivel, M.A. Whooley, K. Dracup, Eur. J. Cardiovasc. Nurs. 14(3), 264-73 (2015)

[18] M. Iakovleva, O. Shchelkova, E. Lubinskaya, O. Nikolaeva, SHS Web Conf. 40, 02011 (2018)

[19] T. Mathes, T. Jaschinski, D. Pieper, Arch. Public. Health. 72(1), 37 (2014)

[20] J. Jin, G.E. Sklar, V. MinSenOh, S.C. Li, Ther. Clin. Risk Manag. 4(1), 269-286 (2008) 